\title{
Iron Deficiency in Heart Failure: Characteristics and Treatment
}

\author{
Ryan C Martin ${ }^{1}$ (1) Dusty Lisi²
}

Accepted: 25 October 2021 / Published online: 25 November 2021

(c) The Author(s), under exclusive licence to Springer Science+Business Media, LLC, part of Springer Nature 2021

\begin{abstract}
Purpose of the Review Iron deficiency in heart failure has been associated with impaired functional capacity and quality of life. The purpose of this paper is to review mechanisms of iron homeostasis and current clinical data exploring mechanisms of iron repletion in heart failure.

Recent Finding Multiple international societies now advise iron repletion for symptomatic heart failure patients with iron deficiency. Due to the chronic inflammation in heart failure, iron deficiency in heart failure is classically defined as ferritin $<100 \mu \mathrm{g} / \mathrm{L}$ or ferritin $100-300 \mu \mathrm{g} / \mathrm{L}$ and transferrin saturation $<20 \%$. Multiple randomized clinical trials have demonstrated benefit from intravenous iron repletion, though studies have predominantly focused on functional capacity and quality of life. A recent study, AFFIRM-AHF, supports the treatment of iron deficiency identified during acute heart failure admissions, noting a reduction in future heart failure hospitalizations. Studies examining iron repletion in patients with heart failure with preserved ejection fraction are currently in process.

Summary Iron homeostasis is maintained predominantly through the regulation of iron absorption, keeping iron levels tightly controlled in the normal state regardless of iron intake. In chronic heart failure however, iron homeostasis becomes dysregulated with resulting iron deficiency in many patients, with and without associated anemia. Iron is a critical element not only for erythropoiesis and oxygen carrying, but also for energy production at the level of the mitochondria and in other cell processes. We thus propose a standardized approach be utilized to screen and treat heart failure patients with iron deficiency.
\end{abstract}

Keywords Iron Deficiency $\cdot$ Heart Failure · Treatment · Intravenous Iron

\section{Introduction}

Heart failure (HF) remains a major cause of hospitalization and death despite advances in medical therapy [1]. Furthermore, advanced HF is associated with progressively worsening quality of life. These findings are exacerbated in the setting of various comorbid conditions. Iron deficiency (ID) in particular has been shown to worsen peak $\mathrm{VO} 2$, shorten 6 min walk distance, and impair overall quality of life. This finding persists regardless of the presence of anemia, indicating an independent mechanism for ID to

This article is part of the Topical Collection on Nutrition, Obesity, and Diabetes

Ryan C Martin

Ryan.Cameron.Martin@Emory.edu

1 Department of Internal Medicine, Division of Cardiology, Emory Healthcare, Atlanta, GA, USA

2 Department of Pharmacy, Emory St. Joseph's Hospital, Atlanta, GA, USA directly impact function in chronic HF [2, 3]. The effects of ID on functional capacity are further magnified in the elderly population due to an overlap with other comorbid conditions. Recent guidelines from major cardiac associations in America and Europe now recommend iron repletion in symptomatic HF patients [4, 5]. In this review, we examine the normal regulatory physiology of iron homeostasis, the definition of ID, and its pathophysiology in HF. We then turn to examine current literature and pharmacotherapy of iron repletion before concluding with recommendations on screening for ID and approaches to iron repletion when indicated.

\section{Iron Homeostasis}

The human body contains on average $3.5-4.5 \mathrm{~g}$ of iron in various forms. The majority of iron is located within erythrocytes as heme for oxygen carrying. The next highest contribution in the body is iron stored as ferritin in the liver [6, 7]. Additional iron is incorporated in 
mitochondria throughout the body in oxidative metabolism and heme production, or provides local oxygen reserves for skeletal muscle as myoglobin. Of the total iron, only a fraction (2-4 mg at any time) circulates in the blood bound to transferrin. Free, unbound iron can be toxic to cells via the development of reactive oxygen species via the Fenton reaction with hydrogen peroxide [8]. Excessive formation of reactive oxygen species leads to uncoupling of the electron transport chain, impairing aerobic metabolism as well as causing other local damage via free radicals. To minimize this, free iron is bound in serum and in the cytoplasm. Iron in the cells is bound in iron-sulfur (Fe-S) complexes or stored in cytoplasmic ferritin. In the serum, iron is transported bound to transferrin or in ferritin to stabilize it. Transferrin carries iron from its absorption in the GI tract, after release from ferritin in hepatocytes, and after being released by macrophages from senescent erythrocytes to various sites throughout the body, predominantly to reticulocytes in the bone marrow for production of heme. In this manner, 20-25 mg of iron passes through the vascular space each day.

Having been a rare element in an individuals' diet for most of human history, the human body efficiently turns iron over, losing only 1-2 mg of its stores each day in normal function. This loss primarily occurs in loss of intestinal enterocytes [9]. Additional iron loss will occur in setting of bleeding [10]. In fact, there are no regulatory systems to increase excretion or metabolism of iron in the human body. Thus, iron regulation is limited to regulating absorption of oral iron. Iron in food is found as bivalent or trivalent iron, and both as ferric complexes or bound up in ferritin. These are broken down and reduced to the bivalent form of iron in the stomach, and are subsequently absorbed by enterocytes in the intestinal epithelium. Iron is then transferred through the cell to the basal cell membrane, where it is transported across by ferroportin. Ferroportin and thus systemic absoprtion is regulated by iron regulatory proteins (IRPs) 1 and 2 and by hepcidin. IRPs act post-transcriptionally on ferroportin mRNA, while hepcidin acts directly on ferroportin post-translationally [10]. Hepatocytes produce and release hepcidin in response to total iron stores, increasing when iron stores are high. Inflammation also triggers hepcidin production via IL-6. Upon release from hepatocytes, hepcidin binds to ferroportin throughout the body, including macrophages and intestinal enterocytes. Hepcidin bound ferroportin is then endocytosed and broken down in lysosomes [9]. In this manner, the majority of iron absorbed in enterocytes does not cross the basal membrane, remaining in the enterocyte until excreted when the enterocyte sloughs off. When ID is present, absorption across enterocytes can increase several fold through suppression of hepcidin production and release by low iron stores $[10,11]$.

\section{Evaluation of Iron Deficiency}

As the majority of total body iron is intracellular and thus not readily measured, surrogates must be used to identify those with ID. Bone marrow aspirate remains the gold standard, though is much more invasive than lab testing and is not feasible to be used routinely. Expert consensus defines ID for inflammatory states such as HF as serum ferritin $<100 \mu \mathrm{g} / \mathrm{L}$ or serum ferritin 100-300 $\mu \mathrm{g} / \mathrm{L}$ and transferrin saturation (TSAT) $<20 \%$ [12•]. This definition of ID captures both absolute ID as well as "functional" ID, in which iron is not released from stores. This results in a lack of available iron for use in oxidative metabolism and erythropoiesis. Per guideline recommendations, levels should be checked annually in patients with HF with NYHA class II or higher.

\section{Heart Failure and Iron Deficiency}

In the setting of HF, $32-57 \%$ of patients were found to have comorbid ID [13]. While there is a higher prevalence of ID in anemic patients, it is still significantly present in non-anemic patients and independently associated with worse outcomes. ID is more prevalent in HF in the setting of anemia as expected but also in females and those with elevated high-sensitivity C-reactive protein, higher NYHA functional class, or elevated $\mathrm{N}$-terminal pro-B type natriuretic peptide (NT-proBNP) [7, 13, 14]. Multiple overlapping mechanisms are theorized to lead to ID in HF: 1) inflammation from chronic HF may increase release of hepcidin, thereby reducing the presence of ferroportin on the duodenal enterocyte basal membranes and macrophages, resulting in the loss of GI absorbed iron and iron reclaimed from macrophages; 2) low flow states and associated early satiety lead to malnutrition and thus poor iron intake; 3 ) edema in gastrointestinal walls may impair absorption from the intestinal lumen; and 4) decreased iron absorption due to proton pump inhibitor use [15]. In a prospective observational trial, Jankowska et al. demonstrated an association of increased high-sensitivity CRP with presence of ID in systolic HF, supporting the theory that inflammation and associated rise in hepcidin leads to ID [13]. However, hepcidin has been shown in some studies to instead be decreased in HF patients with anemia, countering the inflammation theory and instead suggesting the severity of absolute ID may overcome hepcidin stimulation by inflammatory cytokines [16, 17]. More work is needed in this area to clarify the mechanism of ID.

In addition to affecting the oxygen carrying capacity in the blood, ID results in defects in cellular oxidative phosphorylation, leading to impaired energetics and myocardial function with increase in anaerobic glycolysis instead of 
more aerobic and efficient metabolism in the mitochondria via the Krebs cycle [10]. This has been demonstrated to lead to decreased functional capacity as reflected by decreased oxygen consumption ( $\mathrm{pVO} 2)$ and six minute walk test (6MWT) distance. In addition, presence of ID has been noted to carry increased risk of death (all-cause) or heart transplantation (survival at 3 years $53.6 \%$ with ID vs $66.7 \%$ without ID, $p=0.0002$ ), in a multi-variable analysis which demonstrated no such association with advancing age or presence of anemia [13]. Many of the iron repletion trials have also demonstrated increased risk of hospitalization with ID [18, 19]. While a number of analyses have focused on ID in the setting of reduced ejection fraction, little research has extended into heart failure with preserved ejection fraction (HFpEF), despite it being the predominant form of heart failure in older adults [20]. Moliner et al. in a secondary analysis from the DAMOCLES study examined the effect of ID in heart failure with preserved ejection fraction, a prevalent condition amongst older adults with heart failure [21]. In this analysis, 447 HF patients with an average age of 75.7 years $( \pm 9.2)$ were noted to have an $\mathrm{EF}>50 \%$. Of these, ID was identified in $73 \%$. Similar to HFrEF analyses, presence of ID was noted to be associated with decreased 6MWT distance
( 270.7 vs $310.0 \mathrm{~m}, \mathrm{p}=0.005$ ) and reduced quality of life as measured by Minnesota Living with Heart Failure Questionnaire (MLHFQ) with overall scores of 49.4 vs 43.1 in those without ID (higher score connotes worse quality of life, $p=0.01$ ). Of note, the difference in 6MWT distance persisted in non-anemics with HFpEF, though difference in quality of life did not reach statistical significance.

\section{Intravenous Iron Products}

There are various intravenous iron products currently available for administration. The two products that have been most studied in the management of ID anemia in patients who have $\mathrm{HF}$ are ferric carboxymaltose (FCM) and iron sucrose (ISC), summarized in Table 1. The FDA has not approved either of these iron products for ID in HF. FCM is a complex of colloidal iron (III) hydroxide with a carbohydrate polymer (carboxymaltose) [22]. Carboxymaltose facilitates the release of iron. FCM can be administered intravenously as an undiluted bolus as a slow push (every $10 \mathrm{~mL}$ contains $500 \mathrm{mg}$ iron) or diluted as an infusion with $250 \mathrm{~mL}$ of $0.9 \%$ sodium chloride to a concentration $\geq 2 \mathrm{mg} / \mathrm{mL}$. Administration time for the infusion should be $\geq 15 \mathrm{~min}$.

Table 1 Intravenous Iron Supplements used in Iron Deficiency in Heart Failure

\begin{tabular}{|c|c|c|c|c|}
\hline Iron Preparation & FDA Labeled Indication ${ }^{1}$ & $\begin{array}{l}\text { FDA recommended dosing for } \\
\text { IDA }^{1,2}\end{array}$ & $\begin{array}{l}\text { Clinical Study in } \\
\text { Heart Failure }\end{array}$ & $\begin{array}{l}\text { Common Adverse Effects } \\
(>2 \%)\end{array}$ \\
\hline Ferric carboxymaltose (FCM) & $\begin{array}{l}\text { IDA in adults who: } \\
\text { - Unable to tolerate or have } \\
\text { inadequate response to oral } \\
\text { iron } \\
\text { - Have CKD not requiring } \\
\text { dialysis }\end{array}$ & $\begin{array}{l}<50 \mathrm{~kg}: \\
\bullet 15 \mathrm{mg} / \mathrm{kg} \text { body weight in } \\
2 \text { doses separated by } 7 \text { or } \\
\text { more days } \\
\geq 50 \mathrm{~kg} \\
\bullet 750 \mathrm{mg} \text { in } 2 \text { doses sepa- } \\
\text { rated by } 7 \text { or more days for } \\
\text { total dose of } 1500 \mathrm{mg} \mathrm{OR} \\
15 \mathrm{mg} / \mathrm{kg} \text { to a maximum of } \\
1000 \mathrm{mg} \text { as a single-dose } \\
\text { treatment }\end{array}$ & $\begin{array}{l}\text { FAIR-HF } \\
\text { CONFIRM-HF } \\
\text { EFFECT-HF } \\
\text { AFFIRM-AHF }\end{array}$ & $\begin{array}{l}\text { Hypertension } \\
\text { Flushing, } \\
\text { Hypophosphatemia } \\
\text { Erythema } \\
\text { Dizziness } \\
\text { Injection site reaction } \\
\text { Hypersensitivity }^{3}\end{array}$ \\
\hline Iron sucrose (ISC) & IDA in patients with CKD & $\begin{array}{l}\text { - Hemodialysis dependent- } \\
\text { CKD: } 100 \text { mg slow IV } \\
\text { injection or infusion. } \\
\text { Usual treatment course is } \\
1000 \mathrm{mg} \\
\text { - Non-dialysis dependent- } \\
\text { CKD: } 200 \mathrm{mg} \text { slow IV } \\
\text { injection or infusion } \\
\text { - Peritoneal dialysis depend- } \\
\text { ent-CKD: } 300 \text { or } 400 \text { mg } \\
\text { intravenous infusion }\end{array}$ & $\begin{array}{l}\text { Toblli et al } \\
\text { FERRIC-HF }\end{array}$ & $\begin{array}{l}\text { Hypotension } \\
\text { Pruritus } \\
\text { Muscle cramp } \\
\text { Chest, back or joint pain } \\
\text { Diarrhea } \\
\text { Dizziness } \\
\text { Headache } \\
\text { Nausea/Vomiting } \\
\text { Peripheral edema } \\
\text { Injection site reaction } \\
\text { Hypersensitivity }{ }^{3}\end{array}$ \\
\hline
\end{tabular}

CKD Chronic kidney disease, IDA Iron deficiency anemia

${ }^{1}$ FDA approved treatment course/dosing and indication per manufacturer package insert

${ }^{2}$ Treatment course may be repeated if IDA reoccurs

${ }^{3}$ Rare adverse effect of hypersensitivity reaction reported (requires monitoring $30 \mathrm{~min}$ after infusion) 
FCM is available as $750 \mathrm{mg} / 15 \mathrm{~mL}$ and $100 \mathrm{mg} / 20 \mathrm{~mL}$ single-dose vials. Adverse effects that may occur in patients ( $\geq 2 \%$ ) include hypertension, flushing, hypophosphatemia, erythema, dizziness, and injection site reaction. There is a reported risk for hypersensitivity reaction to FCM, and patients should be monitored for 30 min following completion of administration to assure patient tolerance and stability.

ISC is a water soluble complex of poly-nuclear iron (III)hydroxide in sucrose [23]. Once ISC is administered, it separates into iron and sucrose. The iron then forms a complex with transferrin and transported throughout the body. ISC can be administered by slow injection intravenously over 2 to $5 \mathrm{~min}$ or by infusion in a maximum of $100 \mathrm{~mL}$ of $0.9 \% \mathrm{NaCl}$ over $15 \mathrm{~min}$ or longer for doses $\leq 200 \mathrm{mg}$. ISC is available as $50 \mathrm{mg} / 2.5 \mathrm{~mL}, 100 \mathrm{mg} / 5 \mathrm{~mL}$, or $200 \mathrm{mg} / 10 \mathrm{~mL}$ singledose vials. The total treatment dose of ISC for ID anemia is $1000 \mathrm{mg}$ administered over 14 days as five separated doses. There is limited data regarding efficacy and safety with administration of ISC in doses greater than $200 \mathrm{mg}$. The studies evaluating management of ID in patients with HF have not used doses $>200 \mathrm{mg}$ and therefore would not be recommended. Adverse effects that may occur in patients $(\geq 2 \%$ ) include hypotension, pruritus, muscle cramps, chest pain, back pain, arthralgias, diarrhea, dizziness, headache, nausea, vomiting, peripheral edema, and injection site reactions.

Other available intravenous iron products available in the United States include, sodium ferric gluconate, ferumoxytol, and iron dextran. The therapeutic role and safety of these intravenous iron formulations have not been adequately studied for HF patients with ID and would thus not be recommended for management of ID in HF patients.

\section{Clinical Trials Examining Iron Repletion in Heart Failure}

With the significant limitations resulting from ID in HF, multiple trials in recent years have assessed the optimal modality and potential benefits from iron repletion in these patients. The majority of these studies have assessed intravenous formulations, typically FCM. IRONOUT-HF is the only major randomized trial to evaluate the role of oral iron therapy in HF patients with ID [24]. This trial demonstrated no benefit in the administration of oral iron for improved exercise capacity as evaluated by peak $\mathrm{VO}_{2}$. In addition, no differences were observed in the secondary outcomes including exercise capacity, ventilator efficiency, 6MWT, NT-proBNP levels, or Kansas City Cardiomyopathy Questionnaire (KCCQ).

In the major iron repletion trials (see Table 2 for a detailed breakdown), ID as defined above (serum ferritin $<100 \mu \mathrm{g} / \mathrm{L}$ or serum ferritin 100-300 $\mu \mathrm{g} / \mathrm{L}$ and TSAT $<20 \%$ ) was used to identify patients for inclusion in trials, with the exception of Toblli et al. (ferritin $<100 \mu \mathrm{g} / \mathrm{L}$ and TSAT $\leq 20 \%$ ) [3, $18,19,24-26,27 \bullet]$. Further, these studies have consistently focused on HF with at least borderline reduced ejection fraction, focusing on $\mathrm{EF}<45 \%$, with the exception of AFFIRMAHF. Patients evaluated are symptomatic (typically NYHA class II or III) at trial inclusion. For those patients randomized to ID, repletion dosing was based on the Ganzoni formula [3, 25], on hemoglobin and weight [19, 26, 27•], or a set iron dose for all patients [18, 24]. In addition, all trials utilized some variant of an iron maintenance regimen, sometimes guided by ferritin levels, for the remainder of the observation period, which varied between 18 and 52 weeks. All iron repletion regimens were well tolerated without increased risk of adverse effects.

Minimal investigation has been performed on non-FCM iron supplements. Two small studies (40 patients in Toblli et al., 35 in FERRIC-HF) examined the benefit of ISC in HF $[3,18]$. Toblli et al. focused on HF patients with chronic kidney disease (CKD), ID, and anemia. This trial suggested benefit from iron repletion with improvement in biochemical markers of renal function and HF, as well as NYHA functional class. FERRIC-HF in comparison examined anemic and non-anemic HF patients with ID. While it failed to demonstrate improvement in absolute peak oxygen uptake $(\mathrm{mL} / \mathrm{min})$, benefit from ISC was observed when peak oxygen uptake was indexed to patient weight $(\mathrm{mL} / \mathrm{min} / \mathrm{kg}) 18$ weeks after iron repletion therapy was started. Benefit persisted in both anemic and non-anemic patients. Other alternative iron supplements have not been evaluated in HF patients in a large, prospective, randomized format.

The majority of iron trials in HF patients with ID evaluated the effects of FCM. Each of these more recent studies have larger sample sizes, with at least 80 per arm, improving the power of these studies. All of the trials evaluating FCM in HF patients with ID anemia further demonstrated improvement in markers of iron storage (hemoglobin, ferritin, and TSAT). With the exception of AFFIRM-AHF, which assessed the combined clinical endpoint of HF hospitalizations and cardiovascular death, the majority of iron repletion trials utilize surrogates for these less frequent endpoints. Outcomes examined broke down to measures of quality of life or functional capacity. Quality of life measures used include KCCQ, NYHA class, and patient global assessment. Functional capacity was typically determined by either peak oxygen uptake on cardiopulmonary testing or six-minute walk testing (6MWT) distance. IV iron repletion consistently showed improvement in all metrics relative to the placebo controlled group. Benefits were consistently appreciated early on in studies, with most benefit noted at 12-24 weeks from randomization. These benefits are of particular utility to older adults, whose main goals of therapy 


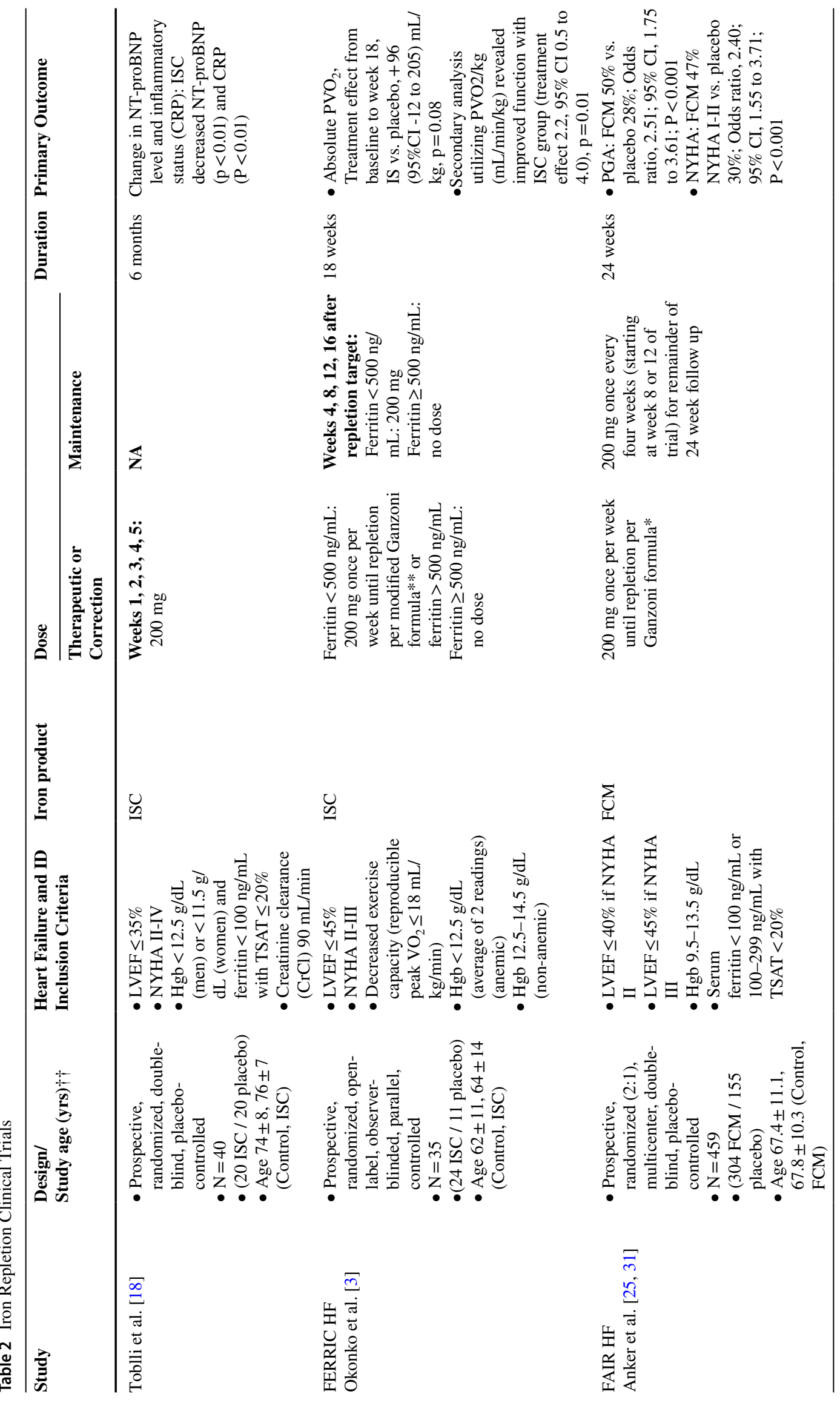




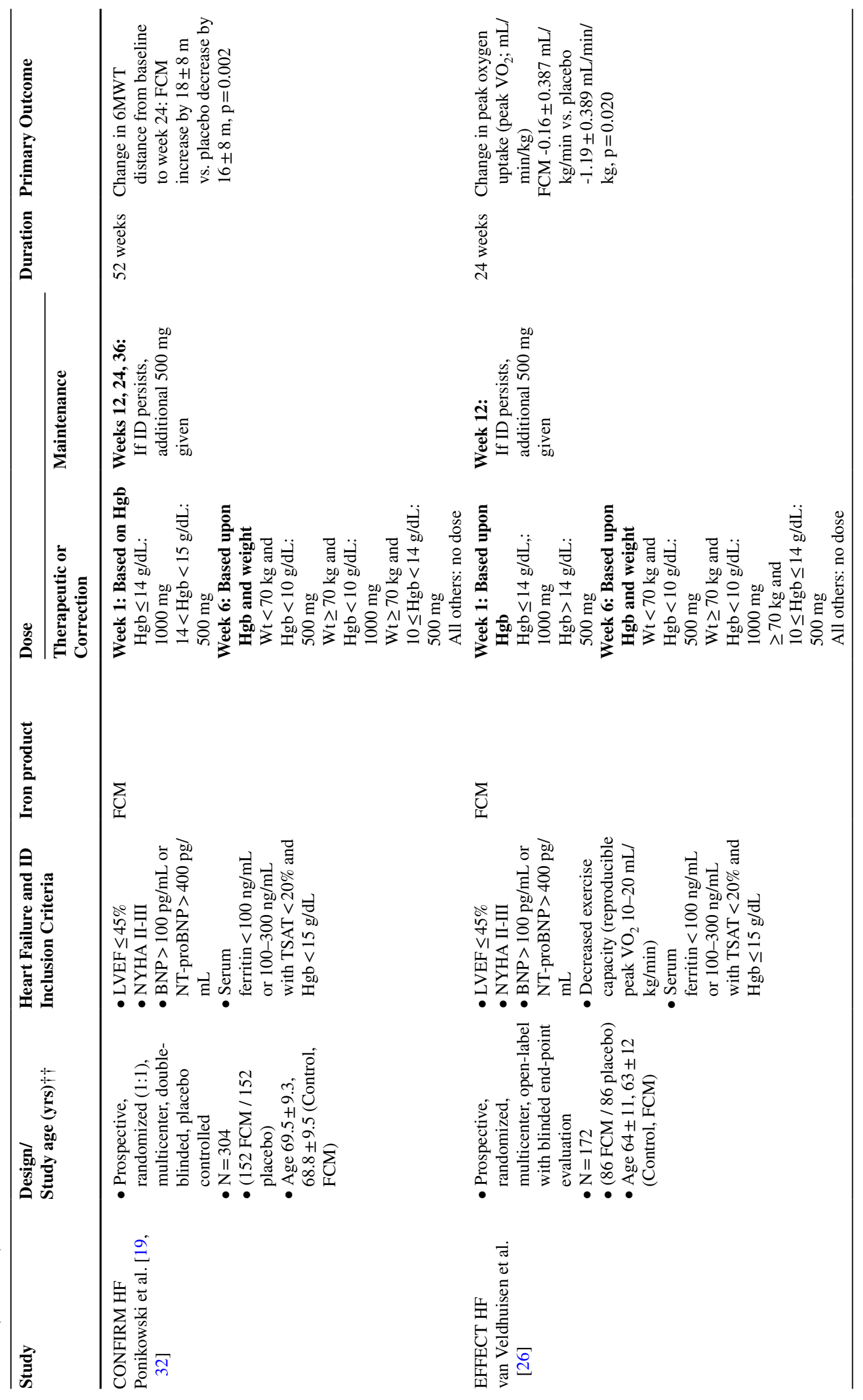




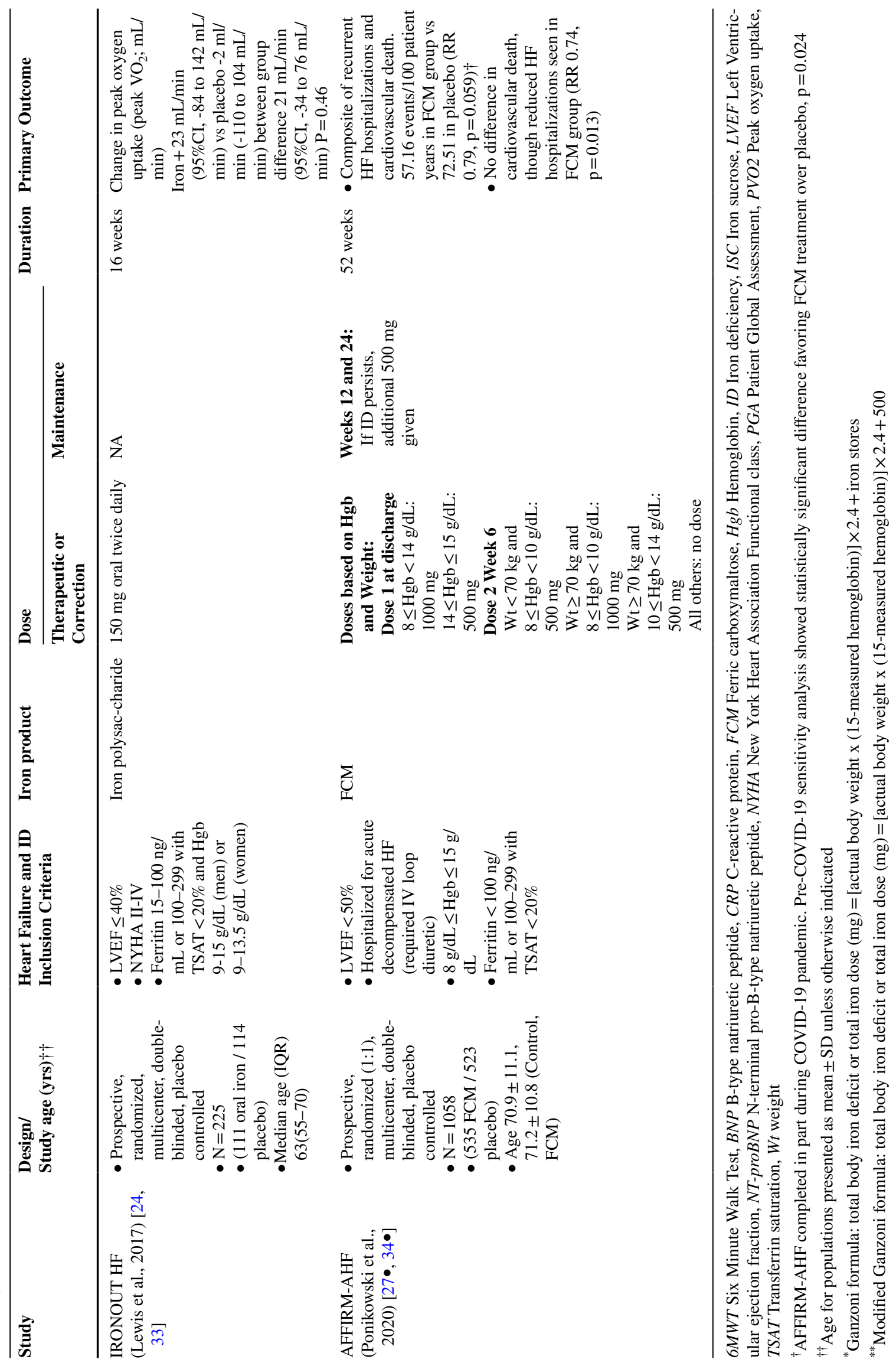


may be quality of life rather than quantity. Effects persisted for duration of each study's follow up period. Some of these studies note a trend in reduced hospitalizations and death with IV iron supplementation, but were not sufficiently powered to reach statistical significance $[19,26]$. Subsequent meta-analyses performed to assess readmissions utilizing early studies supported these noted trends [28, 29].

The most recent IV iron repletion trial, AFFIRM-AHF, uniquely examines clinical endpoints of HF hospitalizations and cardiovascular death as its primary outcome, instead of the surrogate measures of quality of life and measures of functional capacity [27•]. The primary outcome of composite $\mathrm{HF}$ hospitalizations and cardiovascular death trended towards lower risk with FCM therapy, but did not reach clinical significance (Relative risk 0.79, CI 0.62-1.01, $\mathrm{p}=0.059$ ). This finding was secondary to no difference in risk of cardiovascular death. Analyzed independently in secondary analysis, HF hospitalizations were significantly reduced in the FCM group (RR 0.74, CI 0.58-0.94, $\mathrm{p}=0.013$ ). It bears noting that a portion of this trial was ongoing during the COVID-19 pandemic. In subsequent secondary COVID-19 sensitivity analyses, the composite outcome of total HF hospitalizations and cardiovascular death was statistically significant (RR 0.75 , CI $0.59-0.96$, $\mathrm{p}=0.024)$. Of note, additional secondary analyses examining quality of life via the 12-item Kansas City Cardiomyopathy Questionnaire (KCCQ-12) revealed significant improvement in quality of life early after discharge, but this effect attenuated on later follow ups further removed from iron repletion [30]. This reinforces that iron levels should continue to be monitored post repletion and additional infusions provided if ID recurs.

While these studies do not have secondary analyses examining older adults, the study population of many of the studies includes a large proportion of older adults, most notably the larger studies of CONFIRM-HF and AFFIRMAHF. This suggests older adults with HF will likewise realize the benefits to functional capacity, readmission, and quality of life reported on in these studies. While randomized studies to date have focused on HFrEF, there are two studies currently in process to further explore ID in HFpEF (FAIR-HFpEF and PREFER-HF), which anticipate results in 2022.

\section{Iron Status Screening and Repletion: Recommendations}

Given the results from the studies summarized above, we have developed the following approach to identifying ID in our HF patients and approaching iron repletion, building on the recommendations of the international panel of the IRON CORE group [12•]:
- Screen at least annually by checking iron, transferrin or total iron binding content (TIBC), and ferritin.

- If ID identified, we discuss IV iron repletion with the patient. Oral iron may be trialed initially in the outpatient setting if logistical or financial constraints prevent IV repletion. However, as noted in the IRONOUT-HF trial, no significant improvement in peak oxygen uptake or exercise capacity has been demonstrated with oral repletion [24]. If oral iron is trialed, we recheck iron labs at 3 months. If ID persists at this time or oral iron is not tolerated, then IV iron repletion is revisited. FCM is used preferentially, though ISC or other iron formulations are used when FCM is not approved by insurance/available.

- Total repletion amount to be prescribed can be determined by either Ganzoni formula or a blend of weight and hemoglobin, as performed in the clinical trials.

- Routine screening of ferritin should be undertaken during iron repletion in the outpatient setting to avoid iron overload. We follow the standard seen most consistently in the iron repletion trials, holding further infusions if ferritin is $>500 \mu \mathrm{g} / \mathrm{L}$.

- We repeat iron testing 3-6 months after completion of iron repletion. Given known impairments in the absorption of oral iron in chronic HF, we do not routinely prescribe oral iron supplementation following repletion unless the patient has required multiple courses of iron, and this is discontinued if no distinct response is identified.

- If iron levels stabilize, we resume screening annually for ID.

- Initial identification of ID should also prompt appropriate age-related screening for other causes of ID, including occult blood loss via gastrointestinal lesions.

- While we acknowledge the logistics of coordinating iron infusions in the outpatient setting can be challenging at best, we theorize that treating this group of patients, particularly those with NYHA class III or IV, may prevent future admissions. More study is needed to evaluate this hypothetical benefit.

\section{Conclusion}

ID is a significant comorbid condition in chronic HF, associated with worse outcomes including functional capacity and quality of life. Inflammatory factors in chronic HF contribute to the development of ID. This effect is magnified in the elderly population. We recommend introduction of a protocolized approach to ID at the local level to identify these patients early and intervene. Studies examining HFpEF are in process. Additional studies are needed to assess long term effects of iron repletion and the risks and benefits of repeated courses of iron infusions to further our understanding in this area. 
Funding No funding was received to assist in the preparation of this manuscript.

\section{Declarations}

Conflicts of Interest The authors have no relevant financial or nonfinancial interests to disclose.

Human and Animal Rights and Informed Consent This article does not contain any studies with human or animal subjects performed by any of the authors.

\section{References}

Papers of importance have been marked as follows:

- Of importance

1. Virani SS, Alonso A, Aparicio HJ, Benjamin EJ, Bittencourt MS, Callaway CW, et al. Heart Disease and Stroke Statistics-2021 Update: A Report From the American Heart Association. Circulation. 2021;143(8):e254-743. https://doi.org/10.1161/CIR. 0000000000000950 .

2. Jankowska EA, Rozentryt P, Witkowska A, Nowak J, Hartmann $\mathrm{O}$, Ponikowska B, et al. Iron deficiency predicts impaired exercise capacity in patients with systolic chronic heart failure. J Card Fail. 2011;17(11):899-906. https://doi.org/10.1016/j.cardfail. 2011.08.003.

3. Okonko DO, Grzeslo A, Witkowski T, Mandal AK, Slater RM, Roughton M, et al. Effect of intravenous iron sucrose on exercise tolerance in anemic and nonanemic patients with symptomatic chronic heart failure and iron deficiency FERRIC-HF: a randomized, controlled, observer-blinded trial. J Am Coll Cardiol. 2008;51(2):103-12. https://doi.org/10.1016/j.jacc.2007.09.036.

4. Yancy CW, Jessup M, Bozkurt B, Butler J, Casey DE Jr, Colvin MM, et al. 2017 ACC/AHA/HFSA Focused Update of the 2013 ACCF/AHA Guideline for the Management of Heart Failure: A Report of the American College of Cardiology/American Heart Association Task Force on Clinical Practice Guidelines and the Heart Failure Society of America. J Am Coll Cardiol. 2017;70(6):776-803. https://doi.org/10.1016/j.jacc.2017.04.025.

5. Ponikowski P, Voors AA, Anker SD, Bueno H, Cleland JGF, Coats AJS, et al. 2016 ESC Guidelines for the diagnosis and treatment of acute and chronic heart failure: The Task Force for the diagnosis and treatment of acute and chronic heart failure of the European Society of Cardiology (ESC)Developed with the special contribution of the Heart Failure Association (HFA) of the ESC. Eur Heart J. 2016;37(27):2129-200. https://doi.org/10. 1093/eurheartj/ehw128.

6. Ghafourian K, Shapiro JS, Goodman L, Ardehali H. Iron and Heart Failure: Diagnosis, Therapies, and Future Directions. JACC Basic Transl Sci. 2020;5(3):300-13. https://doi.org/10. 1016/j.jacbts.2019.08.009.

7. Nikolaou M, Chrysohoou C, Georgilas TA, Giamouzis G, Giannakoulas G, Karavidas A, et al. Management of iron deficiency in chronic heart failure: Practical considerations for clinical use and future directions. Eur J Intern Med. 2019;65:17-25. https://doi.org/10.1016/j.ejim.2019.05.011.

8. Winterbourn CC. Toxicity of iron and hydrogen peroxide: the Fenton reaction. Toxicol Lett. 1995;82-83:969-74. https://doi. org/10.1016/0378-4274(95)03532-x.
9. Ganz T. Systemic iron homeostasis. Physiol Rev. 2013;93(4):1721-41. https://doi.org/10.1152/physrev.00008. 2013.

10. Paterek A, Mackiewicz U, Maczewski M. Iron and the heart: A paradigm shift from systemic to cardiomyocyte abnormalities. J Cell Physiol. 2019;234(12):21613-29. https://doi.org/10.1002/ jcp.28820.

11. Beaumont C, Delaby C. Recycling iron in normal and pathological states. Semin Hematol. 2009;46(4):328-38. https://doi.org/ 10.1053/j.seminhematol.2009.06.004.

12. Cappellini MD, Comin-Colet J, de Francisco A, Dignass A, Doehner W, Lam CS et al. Iron deficiency across chronic inflammatory conditions: International expert opinion on definition, diagnosis, and management. Am J Hematol. 2017;92(10):106878. https://doi.org/10.1002/ajh.24820. This expert panel defines iron deficiency in chronic inflammatory conditions such as heart failure and propose a screening approach to heart failure patients.

13. Jankowska EA, Rozentryt P, Witkowska A, Nowak J, Hartmann O, Ponikowska B, et al. Iron deficiency: an ominous sign in patients with systolic chronic heart failure. Eur Heart J. 2010;31(15):187280. https://doi.org/10.1093/eurheartj/ehq158.

14. Klip IT, Comin-Colet J, Voors AA, Ponikowski P, Enjuanes C, Banasiak W, et al. Iron deficiency in chronic heart failure: an international pooled analysis. Am Heart J. 2013;165(4):575-82 e3. https://doi.org/10.1016/j.ahj.2013.01.017.

15. Jankowska EA, von Haehling S, Anker SD, Macdougall IC, Ponikowski P. Iron deficiency and heart failure: diagnostic dilemmas and therapeutic perspectives. Eur Heart J. 2013;34(11):816-29. https://doi.org/10.1093/eurheartj/ehs224.

16. Divakaran V, Mehta S, Yao D, Hassan S, Simpson S, Wiegerinck E, et al. Hepcidin in anemia of chronic heart failure. Am J Hematol. 2011;86(1):107-9. https://doi.org/10.1002/ajh.21902.

17. Jankowska EA, Kasztura M, Sokolski M, Bronisz M, Nawrocka $\mathrm{S}$, Oleskowska-Florek W, et al. Iron deficiency defined as depleted iron stores accompanied by unmet cellular iron requirements identifies patients at the highest risk of death after an episode of acute heart failure. Eur Heart J. 2014;35(36):2468-76. https://doi.org/ 10.1093/eurheartj/ehu235.

18. Toblli JE, Lombrana A, Duarte P, Di Gennaro F. Intravenous iron reduces NT-pro-brain natriuretic peptide in anemic patients with chronic heart failure and renal insufficiency. J Am Coll Cardiol. 2007;50(17):1657-65. https://doi.org/10.1016/j.jacc.2007.07. 029.

19. Ponikowski P, van Veldhuisen DJ, Comin-Colet J, Ertl G, Komajda M, Mareev V, et al. Beneficial effects of long-term intravenous iron therapy with ferric carboxymaltose in patients with symptomatic heart failure and iron deficiency. Eur Heart J. 2015;36(11):657-68. https://doi.org/10.1093/eurheartj/ehu385.

20. Dunlay SM, Roger VL, Redfield MM. Epidemiology of heart failure with preserved ejection fraction. Nat Rev Cardiol. 2017;14(10):591-602. https://doi.org/10.1038/nrcardio.2017.65.

21. Alcaide-Aldeano A, Garay A, Alcoberro L, Jimenez-Marrero S, Yun S, Tajes M, et al. Iron Deficiency: Impact on Functional Capacity and Quality of Life in Heart Failure with Preserved Ejection Fraction. J Clin Med. 2020;9(4). https://doi.org/10. 3390/jcm9041199.

22. Injectafer (Ferric Carboxymaltos) [Package Insert]. Switzerland. Vifor International, Inc. 2021.

23. Venofer (Iron Sucrose) [Package Insert]. Switzerland. Vifor International, Inc. 2020.

24. Lewis GD, Malhotra R, Hernandez AF, McNulty SE, Smith A, Felker GM, et al. Effect of Oral Iron Repletion on Exercise Capacity in Patients With Heart Failure With Reduced Ejection Fraction and Iron Deficiency: The IRONOUT HF Randomized 
Clinical Trial. JAMA. 2017;317(19):1958-66. https://doi.org/ 10.1001/jama.2017.5427.

25. Anker SD, Comin Colet J, Filippatos G, Willenheimer R, Dickstein $\mathrm{K}$, Drexler H, et al. Ferric carboxymaltose in patients with heart failure and iron deficiency. N Engl J Med. 2009;361(25):2436-48. https://doi.org/10.1056/NEJMoa0908355.

26. van Veldhuisen DJ, Ponikowski P, van der Meer P, Metra M, Bohm M, Doletsky A, et al. Effect of Ferric Carboxymaltose on Exercise Capacity in Patients With Chronic Heart Failure and Iron Deficiency. Circulation. 2017;136(15):1374-83. https://doi. org/10.1161/CIRCULATIONAHA.117.027497.

27. Ponikowski P, Kirwan BA, Anker SD, McDonagh T, Dorobantu M, Drozdz J, et al. Ferric carboxymaltose for iron deficiency at discharge after acute heart failure: a multicentre, double-blind, randomised, controlled trial. Lancet. 2020;396(10266):1895904. https://doi.org/10.1016/S0140-6736(20)32339-4. The only randomized control trial to assess benefit of iron repletion on acute decompensated heart failure. Technically a negative study, but with a clinically important reduction in HF hospitalizations on secondary analysis. Trial results impacted in part by COVID-19 pandemic.

28. Anker SD, Kirwan BA, van Veldhuisen DJ, Filippatos G, CominColet J, Ruschitzka F, et al. Effects of ferric carboxymaltose on hospitalisations and mortality rates in iron-deficient heart failure patients: an individual patient data meta-analysis. Eur J Heart Fail. 2018;20(1):125-33. https://doi.org/10.1002/ejhf.823.

29. Jankowska EA, Tkaczyszyn M, Suchocki T, Drozd M, von Haehling S, Doehner W, et al. Effects of intravenous iron therapy in iron-deficient patients with systolic heart failure: a meta-analysis of randomized controlled trials. Eur J Heart Fail. 2016;18(7):786-95. https://doi.org/10.1002/ejhf.473.

30. Jankowska EA, Kirwan BA, Kosiborod M, Butler J, Anker SD, McDonagh $\mathrm{T}$, et al. The effect of intravenous ferric carboxymaltose on health-related quality of life in iron-deficient patients with acute heart failure: the results of the AFFIRM-AHF study. Eur Heart J. 2021. https://doi.org/10.1093/eurheartj/ehab234.

31. Anker SD, Colet JC, Filippatos G, Willenheimer R, Dickstein $\mathrm{K}$, Drexler H, et al. Rationale and design of Ferinject assessment in patients with IRon deficiency and chronic Heart Failure (FAIR-HF) study: a randomized, placebo-controlled study of intravenous iron supplementation in patients with and without anaemia. Eur J Heart Fail. 2009;11(11):1084-91. https://doi.org/ 10.1093/eurjhf/hfp140.

32. Ponikowski P, van Veldhuisen DJ, Comin-Colet J, Ertl G, Komajda $\mathrm{M}$, Mareev V, et al. Rationale and design of the CONFIRM-HF study: a double-blind, randomized, placebo-controlled study to assess the effects of intravenous ferric carboxymaltose on functional capacity in patients with chronic heart failure and iron deficiency. ESC Heart Fail. 2014;1(1):52-8. https://doi.org/10.1002/ ehf 2.12006 .

33. Lewis GD, Semigran MJ, Givertz MM, Malhotra R, Anstrom KJ, Hernandez AF, et al. Oral Iron Therapy for Heart Failure With Reduced Ejection Fraction: Design and Rationale for Oral Iron Repletion Effects on Oxygen Uptake in Heart Failure. Circ Heart Fail. 2016;9(5). https://doi.org/10.1161/CIRCHEARTFAILURE. 115.000345.

34.• P Ponikowski BA Kirwan SD Anker M Dorobantu J Drozdz V Fabien et al 2019 Rationale and design of the AFFIRM-AHF trial: a randomised, double-blind, placebo-controlled trial comparing the effect of intravenous ferric carboxymaltose on hospitalisations and mortality in iron-deficient patients admitted for acute heart failure Eur J Heart Fail 211216511658 https://doi. org/10.1002/ejhf.1710. Details an iron repletion regimen that can be implemented in clinical practice.

Publisher's Note Springer Nature remains neutral with regard to jurisdictional claims in published maps and institutional affiliations. 